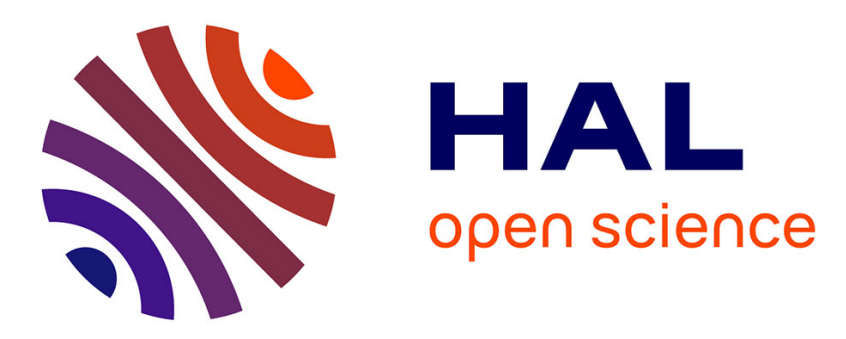

\title{
From algal polysaccharides to cyclodextrins to stabilize a urease inhibitor.
}

\author{
Danièle Pro, Samuel Huguet, Mustapha Arkoun, Caroline Nugier-Chauvin, \\ Jose María García-Mina, Alain Ourry, Dominique Wolbert, Jean-Claude Yvin, \\ Vincent Ferrières
}

\section{To cite this version:}

Danièle Pro, Samuel Huguet, Mustapha Arkoun, Caroline Nugier-Chauvin, Jose María García-Mina, et al.. From algal polysaccharides to cyclodextrins to stabilize a urease inhibitor.. Carbohydrate Polymers, 2014, 112, pp.145-51. 10.1016/j.carbpol.2014.05.075 . hal-01063896v2

\section{HAL Id: hal-01063896 https://hal.science/hal-01063896v2}

Submitted on 14 Oct 2014

HAL is a multi-disciplinary open access archive for the deposit and dissemination of scientific research documents, whether they are published or not. The documents may come from teaching and research institutions in France or abroad, or from public or private research centers.
L'archive ouverte pluridisciplinaire HAL, est destinée au dépôt et à la diffusion de documents scientifiques de niveau recherche, publiés ou non, émanant des établissements d'enseignement et de recherche français ou étrangers, des laboratoires publics ou privés. 
1

2

3

5

7

8

\section{Highlights}

- A new formulation of NBPT, a known urease inhibitor, with cyclodextrin was prepared

- The complex CD/NBPT was fully characterized

- The stability of NBPT and that of CD/NBPT in acidic media were studied by NMR

- $\mathrm{IC}_{50}$ of the CD/NBPT complex was determined 


\section{From algal polysaccharides to cyclodextrins to stabilize a urease inhibitor}

10

Danièle Pro, ${ }^{\mathrm{a}, \mathrm{b}}$ Samuel Huguet, ${ }^{\mathrm{a}, \mathrm{b}}$ Mustapha Arkoun, ${ }^{\mathrm{c}, \mathrm{d}}$ Caroline Nugier-Chauvin, ${ }^{\mathrm{a}, \mathrm{b}}$ José Maria Garcia-Mina, ${ }^{\mathrm{e}}$ Alain Ourry, ${ }^{\mathrm{c}, \mathrm{d}}$ Dominique Wolbert, ${ }^{\mathrm{a}, \mathrm{b}}$ Jean-Claude Yvin, ${ }^{\mathrm{f}}$ Vincent

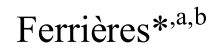

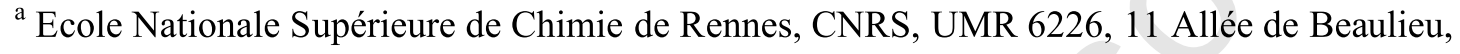
CS 50837, 35708 Rennes Cedex 7, France

${ }^{\mathrm{b}}$ Université européenne de Bretagne, France

${ }^{\mathrm{c}}$ Université de Caen Basse-Normandie, UMR 950 Ecophysiologie Végétale, Agronomie et nutritions N, C, S. Esplanade de la paix, 14032 Caen, France

${ }^{\mathrm{d}}$ INRA, UMR 950 Ecophysiologie Végétale, Agronomie et nutritions N, C, S. Esplanade de la paix, 14032 Caen, France

e Timac Agro International, Poligono de Arazuri-Orcoyen Calle C n³2 E-31160 Orcoyen, Spain

${ }_{\mathrm{f}}^{\mathrm{f}}$ Timac Agro International, 27 Avenue Franklin Roosevelt, 35408 Saint Malo, France

Corresponding author: Vincent Ferrières

Tel: (+33) 23238058

Fax: (+33) 223238199

vincent.ferrieres@ensc-rennes.fr 


\section{From algal polysaccharides to cyclodextrins to stabilize a urease inhibitor}

Danièle Pro, ${ }^{\mathrm{a}, \mathrm{b}}$ Mustapha Arkoun, ${ }^{\mathrm{c}, \mathrm{d}}$ Caroline Nugier-Chauvin, ${ }^{\mathrm{a}, \mathrm{b}}$ José Maria Garcia-Mina, Alain Ourry, ${ }^{\mathrm{c}, \mathrm{d}}$ Jean-Claude Yvin, ${ }^{\mathrm{f}}$ Vincent Ferrières ${ }^{*, \mathrm{a}, \mathrm{b}}$

${ }^{a}$ Ecole Nationale Supérieure de Chimie de Rennes, CNRS, UMR 6226, 11 Allée de Beaulieu, CS 50837, 35708 Rennes Cedex 7, France

${ }^{\mathrm{b}}$ Université européenne de Bretagne, France

${ }^{\mathrm{c}}$ Université de Caen Basse-Normandie, UMR 950 Ecophysiologie Végétale, Agronomie et nutritions N, C, S. Esplanade de la paix, 14032 Caen, France

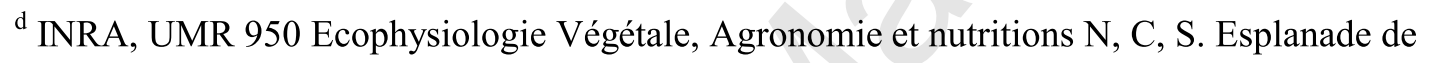
la paix, 14032 Caen, France

${ }^{\text {e }}$ Timac Agro International, Poligono de Arazuri-Orcoyen Calle C n³2 E-31160 Orcoyen, Spain

${ }^{\mathrm{f}}$ Timac Agro International, 27 Avenue Franklin Roosevelt, 35408 Saint Malo, France

Abstract: $N$-Butyl-phosphorotriamide (NBPT) is a fertilizer widely used for its urease inhibiting properties. Nevertheless, formulations currently commercialized are complex and do not avoid severe decrease of activity due to the low stability of the bioactive compound under acidic conditions. According to its structure, NPBT was thought to be able to interact with both polar additives, by its phosphoramide function, and hydrophobic ones, through its alkyl chain. In this context, and in order to simplify formulations of this bioactive compound, a panel of natural polysaccharides was studied, including starch, $\beta$-(1,3)-glucans, carraghenans and alginates. We also used cyclodextrins, characterized the most stable 
inclusion complex with $\alpha$-cyclodextrin and evaluated the stability of NBPT thus protected against hydrolysis under acidic conditions.

Keywords: NBPT; Carraghenans; Alginates; (1,3)-Glucans; Starch; Cyclodextrins

\section{Introduction}

The small molecule of urea is the source of two major scientific discoveries. Not only it is the first molecule chemically synthesized by Wöhler in 1828 , but the study of its biodegradation allowed the first crystallization of an enzyme, the Jack Bean urease, in 1926 by Summer (Sumner, 1926), who was subsequently awarded by the Nobel Prize for this breakthrough in 1946. Meantime, urea has become an important component of many fertilizers. However, as only $30 \%$ of the available nitrogen is absorbed by plants, improving the efficiency of the nitrogen use in agriculture generally requires adding inhibitors acting on nitrification and/or ureases. The application of the latter significantly reduces ammonia volatilization, as well as damages to seedlings. Plants are also able to assimilate nitrogen as urea, and urease inhibitors promote this type of nutrition, which is also beneficial for plant growth (Trenkel, 2010). Finally, the use of such compounds able to increase the lifetime of urea in soils is not exclusive to agriculture, but find applications in dairy farming where they can significantly decrease nitrogen emissions due to urine and manure (Leinker, Reinhardt-Hanisch, Hartung \& von Borell, 2005; Zaman, Nguyen, Blennerhassett \& Quin, 2008).

Numerous studies have led to the marketing of a large panel of molecules having anti-ureasic activities [for instance hydroquinone, phosphotriamide compounds (Domínguez et al., 2008; Font et al., 2008; Trenkel, 2010)], or able to influence nitrification phenomena [ammonium thiosulfate, thiourea, or more complex products, i.e. pyrimidinic, triazolic, thiadiazolic derivatives, dicyandiamide (DCD) (Nelson \& Huber, 1992; Trenkel, 2010)], both contributing 
to improve nitrogen absorption by plants. In addition to the range of such bioactive molecules, many formulations are proposed. Inhibitors may be available as pure compounds or directly incorporated into fertilizers. They can also be formulated in liquid or solid phases. This allows matching a wide range of treatments to soil characteristics and infrastructure of the users. For instance, commercial forms of DCD are an excellent example of adaptability, since it is possible to obtain this single molecule or in combination with other inhibitors of nitrification possibly mixed with urea, or even incorporated into fertilizers containing ammonium salts and many other nutrients. Similarly, $N$-butyl-thiophosphotriamide (NBPT) can be purchased in a liquid formulation (Agrotain), but also in a solid one containing DCD, or in solid granules with urea and DCD. Consequently, commercially available inhibitors stabilize nitrogen for several days to several weeks.

The development of new compounds and/or formulations is part of an integrated approach to farming, keeping in mind that control of the global impact on environment is a priority. However, decades of use of urease inhibitors, and of basic researches, highlighted the complexity of using them efficiently. Among influencing parameters are the quality of soils $(\mathrm{pH}$, nature of the organic matter and possibility to find colloids, porosity, biodiversity linked with numerous microorganisms), abiotic factors (temperature, water quality), and own properties of the inhibitors (volatility, hydrophilic/hydrophobic balance, stability and mobility in soils) (Subbarao et al., 2006). In this context, we have initiated a program and first proposed to covalently connect known nitrification inhibitors to mono- and disaccharides, especially in order to increase their ecocompatibility (Pro et al., 2012). Herein, we propose another approach lying on the opportunity to formulate the known urease inhibitor NBPT (Fig. 1) with natural polysaccharides and derivatives thereof. It is recognized that NBPT has already inhibition properties $\left(\mathrm{IC}_{50}=100 \mathrm{nM}\right)$, but this thiophosphoramide is readily converted 
into its $O$-counterpart NBPTO that is the real inhibitor in soils $\left(\mathrm{IC}_{50}=1 \mathrm{nM}\right)$. However, two major limitations are generally encountered with this inhibitor patented in 1985 (Kolc, Swerdloff, Rogic, Hendrickson \& Van Der Puy, 1985): the first one is its hydrophobicity that requires more or less complex formulations, and the second but more limiting one relies on its low stability, and so loss of activity, in acidic media (Domínguez et al., 2008). The ability of carbohydrates to adopt many conformations, and/or to interact with their aqueous environment (basic vs. acidic, presence of salts) (Cui, 2005 ), offers great opportunities to develop new formulations.

\section{Phosphotriamide}

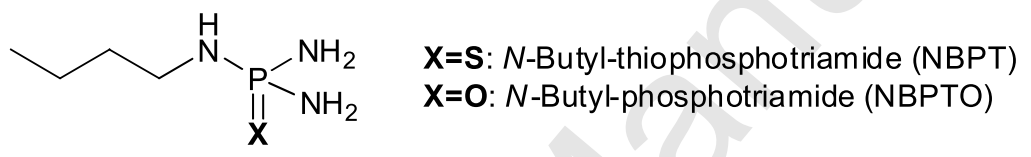

Fig.1. Structure of the studied urease inhibitor NBPT.

\section{Material and methods}

\subsection{Materials}

Polysaccharides used in this study are commercially available. NBPT was provided by Timac Agro International (Dinard) and was further purified by recristallisation from water. ${ }^{1} \mathrm{H},{ }^{13} \mathrm{C}$, ${ }^{31} \mathrm{P}$ NMR spectra were recorded with a Brüker ARX 400 spectrometer at $400 \mathrm{MHz}, 100 \mathrm{MHz}$, and $162 \mathrm{MHz}$ for ${ }^{1} \mathrm{H},{ }^{13} \mathrm{C}$ and ${ }^{31} \mathrm{P}$, respectively. Chemical shifts are given in $\delta$ units (ppm). Coupling constants $J$ were calculated in Hertz $(\mathrm{Hz})$. Abbreviations were used to precise signal multiplicity: s (singulet), d (doublet), t (triplet), m (multiplet), dd (double doublet)... The HRMS were measured at the Centre Regional de Mesures Physiques de l'Ouest (CRMPO, Université de Rennes 1) with a MS/MS ZabSpec TOF Micromass using $m$-nitrobenzylic alcohol as a matrix and accelerated caesium ions for ionization. 


\subsection{Degradation tests in acidic media by ${ }^{31} P N M R$}

The necessary amount of formulation for having $10 \mathrm{mg}$ of NBPT was mixed with $250 \mu \mathrm{L}$ water in NMR tubes (blank solution consisted in $40 \mathrm{mg}$ Agrotain in $250 \mu \mathrm{L}$ of water). The solution was heated until complete dissolution of NBPT. $250 \mu \mathrm{L}$ of acidic buffer solution $\left(\mathrm{CH}_{3} \mathrm{COOH} / \mathrm{CH}_{3} \mathrm{COONa}, 500 \mathrm{mM}, \mathrm{pH} 5.5\right)$ was added. Then, a fused capillary containing a invariant $\mathrm{H}_{3} \mathrm{PO}_{4}$ solution in $\mathrm{D}_{2} \mathrm{O}$ was inserted, and the degradation of NBPT was monitored by ${ }^{31} \mathrm{P}$ NMR. The degradation of NBPT was deduced from the decrease of the signal at 60.5 ppm (corresponding to the NBPT) compared to the constant -0.3 ppm peak's area (corresponding to the $\mathrm{H}_{3} \mathrm{PO}_{4}$ ).

\subsection{Formulations with cyclodextrin $C D \alpha$ and determination of the inclusion complex thanks} to the Job's method

A solution of $\alpha$-cyclodextrin $(\mathrm{CD} \alpha)$ in water $(10 \mathrm{mM})$ and a solution of NBPT in methanol $(10 \mathrm{mM})$ were prepared. Different ratio of both solutions were mixed together in test tubes (from 0:10 to 10:0), for a total volume of $1 \mathrm{~mL}$, before freeze-drying. The resulting solid was dissolved into $1 \mathrm{~mL}$ of $\mathrm{D}_{2} \mathrm{O}$, and analyzed by ${ }^{1} \mathrm{H}$ NMR. For each ratio of NBPT ( $r$, Eq. 1$)$ and for each proton $(i)$ of NBPT, the variation of chemical shift $\left(\Delta \delta_{r}^{i}\right)$ was calculated as (Eq. 1):

$$
r=[\mathrm{NBPT}] /([\mathrm{NBPT}]+[\mathrm{CD} \alpha](\text { Eq. } 1)
$$

$$
\Delta \delta_{\mathrm{r}}^{\mathrm{i}}=\delta_{\mathrm{r}}^{\mathrm{i}}-\delta_{1}^{\mathrm{i}}(\text { Eq. 2) }
$$

For each ratio of $\mathrm{CD} \alpha(1-\mathrm{r})$ and for each proton $(j)$ of $\mathrm{CD} \alpha$, the variation of chemical shift $\Delta \delta^{\mathrm{i}}{ }_{1-\mathrm{r}}$ was calculated as (Eq. 3):

$$
\Delta \delta_{1-\mathrm{r}}^{\mathrm{j}}=\delta_{1-\mathrm{r}}^{\mathrm{j}}-\delta_{0}^{\mathrm{j}}(\text { Eq. 3) }
$$

Then $r . \Delta \delta_{\mathrm{r}}^{\mathrm{i}}$ and (1-r). $\Delta \delta_{1-\mathrm{r}}^{\mathrm{j}}$ were plotted against $r$. Resulting curves went through a maximum, at the $r$ value corresponding to the ratio of the inclusion complex. 


\subsection{Determination of the association constant}

The association constant was obtained according to the method of Benesi-Hildebrand (Benesi \& Hildebrand, 1949). A solution of NBPT in methanol (5 mM) and a solution of CD- $\alpha$ in water $(125 \mathrm{mM})$ were prepared. Different amounts of these two solutions were mixed with water for a total volume of $500 \mu \mathrm{L}$, a constant concentration of NBPT (1 mM), and a varying concentration of CD- $\alpha$ (from 50 to $100 \mathrm{mM}$ ).

Then, mixtures were freeze-dried and the resulting solid dissolved into $500 \mu \mathrm{L}$ of $\mathrm{D}_{2} \mathrm{O}$, before ${ }^{1} \mathrm{H}$ NMR analysis. For each concentration of CD- $\alpha$ ([CD- $\left.\left.\alpha\right]\right)$, and for each proton $(i)$ of NBPT, the variation of chemical shift $\Delta \delta_{[\mathrm{CD}-\alpha]}^{\mathrm{i}}$ was calculated thanks to equation 4 :

$$
\Delta \delta_{[\mathrm{CD}-\alpha]}^{\mathrm{i}}=\delta_{[\mathrm{CD}-\alpha]}^{\mathrm{i}}-\delta_{0}^{\mathrm{i}}(\mathrm{Eq} .4)
$$

Then, $1 / \Delta \delta_{[C D-\alpha]}^{i}$ was plotted against $1 /[C D-\alpha]$. Resulting curves obey to a linear equation. The association constant of the complex $\left(K_{a}\right)$ and the variations of chemical shifts of NBPT in the pure complex $\left(\Delta \delta_{\text {Cpx }}^{i}\right)$ were deduced from equations of the intercept and the slope of the curves:

$$
\text { intercept }=1 / \Delta \delta_{\mathrm{Cpx}}^{\mathrm{i}}\left(\text { Eq. 5) and slope }=1 / K_{a} \cdot \Delta \delta_{\mathrm{Cpx}}^{\mathrm{i}}(\mathrm{Eq} .6)\right.
$$

This method was applied on the four signals corresponding to the butyl chain of the NBPT. The four estimations of the association constant were averaged.

\subsection{Evaluation of the inhibitory activity}

One milliliter of buffer solution $\left(\mathrm{KH}_{2} \mathrm{PO}_{4} / \mathrm{K}_{2} \mathrm{HPO}_{4}, 70 \mathrm{mM}, \mathrm{pH} 7\right), 1 \mathrm{~mL}$ of inhibitor solution (at different concentrations), and $10 \mu \mathrm{L}$ of jack bean urease solution $(2.8 \mathrm{mg} / \mathrm{mL}$, Sigma U150035.500 ) were mixed in test tubes and incubated for $30 \mathrm{~min}$ at $37{ }^{\circ} \mathrm{C}$ (blank solution consisted of the same mixture without inhibitor). Afterward, $1 \mathrm{~mL}$ of urea solution $(6 \mathrm{mg} / \mathrm{mL})$ was added, with incubation again for $30 \mathrm{~min}$ at $37^{\circ} \mathrm{C}$. The reaction was stopped by the 
addition of $2 \mathrm{~mL}$ of $0.033 \mathrm{~N} \mathrm{HCl}$. Each inhibitor dose was tested in triplicate. The level of ammonium released was determined photometrically, using the ammonium Test from Merck (Ref 1.14752.0001). The inhibition percentage $\operatorname{Inh}(\%)$ was calculated as:

$$
\operatorname{Inh}(\%)=100-100\left(\mathrm{~A}_{\text {Inh }} / \mathrm{A}_{\mathrm{B}}\right)(\text { Eq. 7) }
$$

where $A_{I n h}$ and $A_{B}$ are the absorbance at $692 \mathrm{~nm}$ in the test tubes, with and without inhibitor, respectively.

\section{Results and discussion}

Before managing formulations with polysaccharides, a simple method for monitoring degradation of NBPT, solubilized in a solvent, under acidic conditions was developed. While some analysis were already proposed (Abraham, Benson \& Jardine, 1983; Douglass \& Hendrickson, 1991), NMR data, and more especially ${ }^{31} \mathrm{P}$ NMR in the case of phosphorouscontaining compounds, offers the opportunity to also give structural data of resulting products (Fig. 2). In order to mimic acidic soils, this study was therefore performed in an acetate buffer at $\mathrm{pH} 5.5$ over one week. It was firstly observed that the intensity of the initial signal at nearly $60 \mathrm{ppm}$ disappeared in favor of another one at $53 \mathrm{ppm}$. Secondly, no more NBPT could be detected after one week in this medium. Moreover, the high field chemical shift corresponding to the newly formed compound indicated a break of at least one P-N linkage, substituted by a P-O bond. This result was subsequently complemented and corroborated by a high resolution mass spectrometry (HRMS) analysis (Fig. 2). Indeed, two peaks at m/z 111.56 and 73.87 appeared, thus demonstrating the apparition of diamoniphosphoric acid (DATP) and $n$-butylamine, respectively. This showed the favored cleavage between the $\mathrm{P}$ atom and the $\mathrm{N}$ one connected to the butyl chain, both $\mathrm{P}-\mathrm{NH}_{2}$ linkages remaining stable. Moreover, under the conditions used, no NBPTO was observed. That means that the $\mathrm{P}=\mathrm{S}$ bond in stable under conditions used and that $\mathrm{S} / \mathrm{O}$ exchange occurs only in soils, probably thanks to bacterial 
204

205

206

207

208
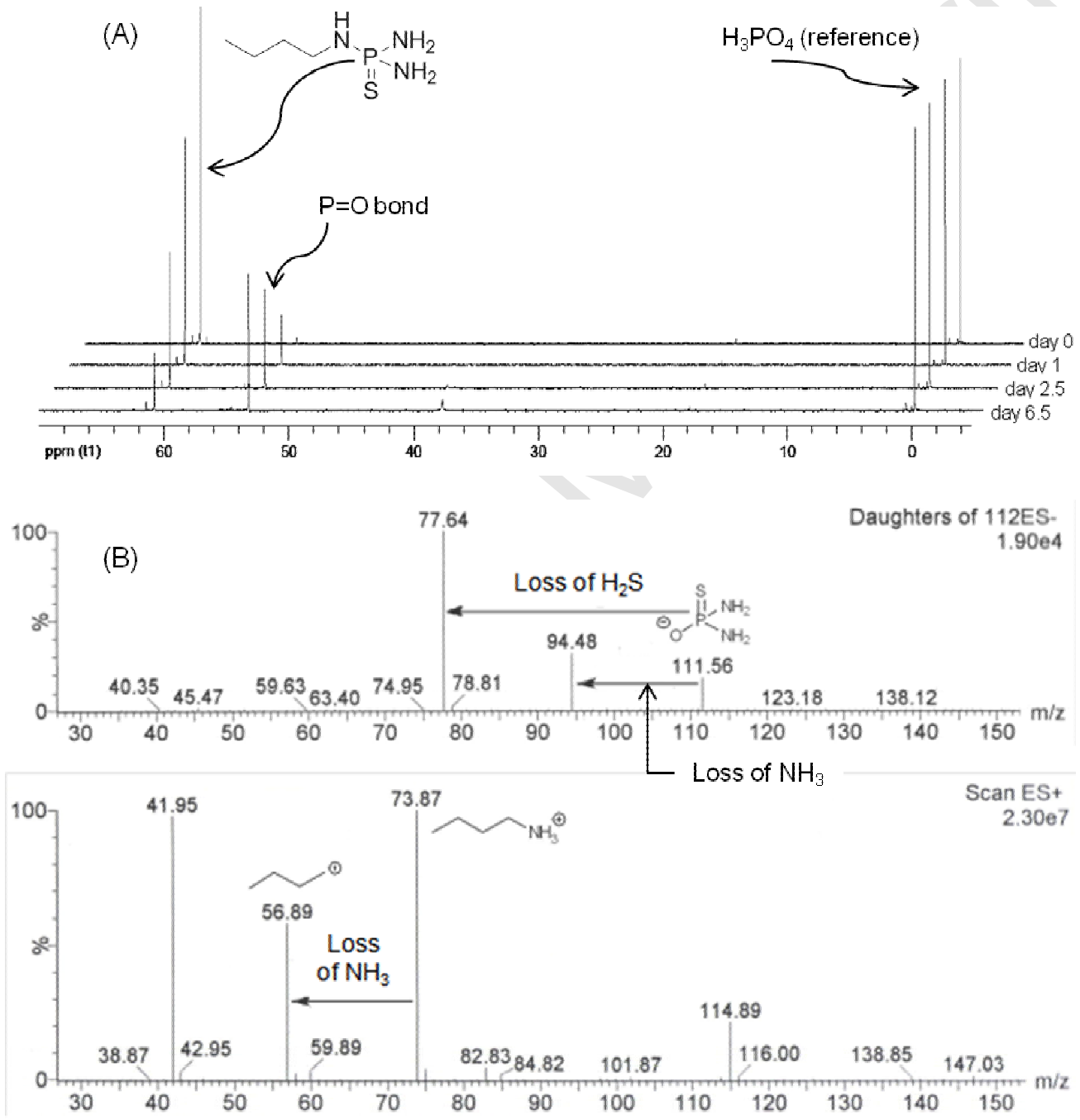

activity. Finally, the monitoring of the degradation of NBPT over one week allowed us to show that it followed a first order kinetics at $\mathrm{pH} 5.5\left(\mathrm{k}=2.2 \times 10^{-6} \pm 0.8 \times 10^{-6} \mathrm{~s}^{-1}, \mathrm{n}=15\right.$; See Supplementary materials).

Fig. 2. (A) ${ }^{31} \mathrm{P}$ NMR monitoring and (B) HRMS analysis of the degradation of NBPT at $\mathrm{pH}$ 
With this analytical method in hand, it was further planned to build the inhibitor around an environment conductive to its preservation in acidic media. However, NBPT must remain free in order to emerge this background, and be gradually released to exert the desired biological function on urease. On the basis of conformational and physico-chemical adaptability of polysaccharides, we first studied carraghenans (Fig. 3), well known carbohydrates extracted from red seaweeds Rhodophyceae. $\mathrm{\kappa}$ - and $\mathrm{\imath}$-Carraghenans are characterized by sequence of Dgalactopyranosyl (D-Galp) residues having alternatively ${ }^{4} \mathrm{C}_{1}$ and ${ }^{1} \mathrm{C}_{4}$ conformations, the latter resulting from a 3,6-anhydro-bridge, and they can adopt double strand conformations. $\lambda$ Carraghenans are also built of sulfated D-Gal $p$ entities, but differ from the latter families by the absence of anhydro-bridge and by the number of anionic groups, thus resulting in tertiary ribbon structure (Cui, 2005 ). Despite their charges, carraghenans are able to interact with small volatile compounds (Hambleton, Fabra, Debeaufort, Dury-Brun \& Voilley, 2009). We thus hypothesized that it could possibly interact either with the butyl chain of NBPT, even weakly, or also with the more polar phosphoramide part of the inhibitor, or both functions. On this basis, the studied inhibitor was dissolved in saturated solution of $\kappa-$, - 1 or $\lambda$-carraghenans buffered at $\mathrm{pH}$ 5.5. Its degradation was monitored by ${ }^{31} \mathrm{P}$ NMR and compared to that of NBPT formulated as Agrotain. Unfortunately, no protecting effect was observed and the disappearance of NBPT in carbohydrate solutions over a period of 6 days followed a kinetic comparable with that of commercially available formulation (See Supplementary Materials). 


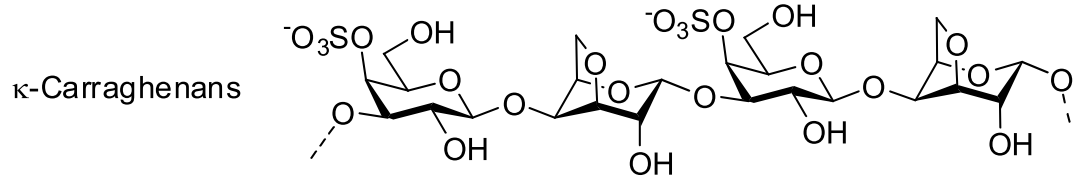

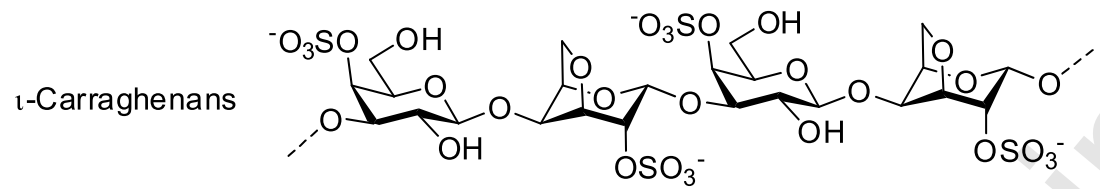

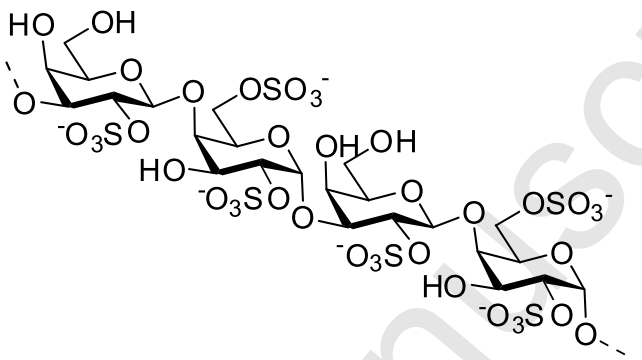

Fig. 3. Primary structures of $\kappa-$, $1-$, and $\lambda$-carraghenans.

In a second stage, alginates were also tried to potentially carry the target thiophosphoramide.

As carraghenans, they present anionic groups, i.e. carboxylates, but not sulfates. We thus anticipated that carboxylate groups in alginates could quench some protons from the media, thus preventing NBPT hydrolysis. Moreover, L-guluronic entities, but not D-mannuronic residues, may form cavities which can accommodate divalent cations such as calcium (Fig. 4). Thus, in the presence of calcium salts, the polyguluronic chains gather around cations, creating a network of channels with some facial amphiphilicity. We have however observed no significant improvement of the formulations, using alginates alone or these polysaccharides in the presence of calcium salts to provide beads. The latter cannot retain efficiently the NBPT molecules since they diffuse into the aqueous solution within only a few minutes. 
246
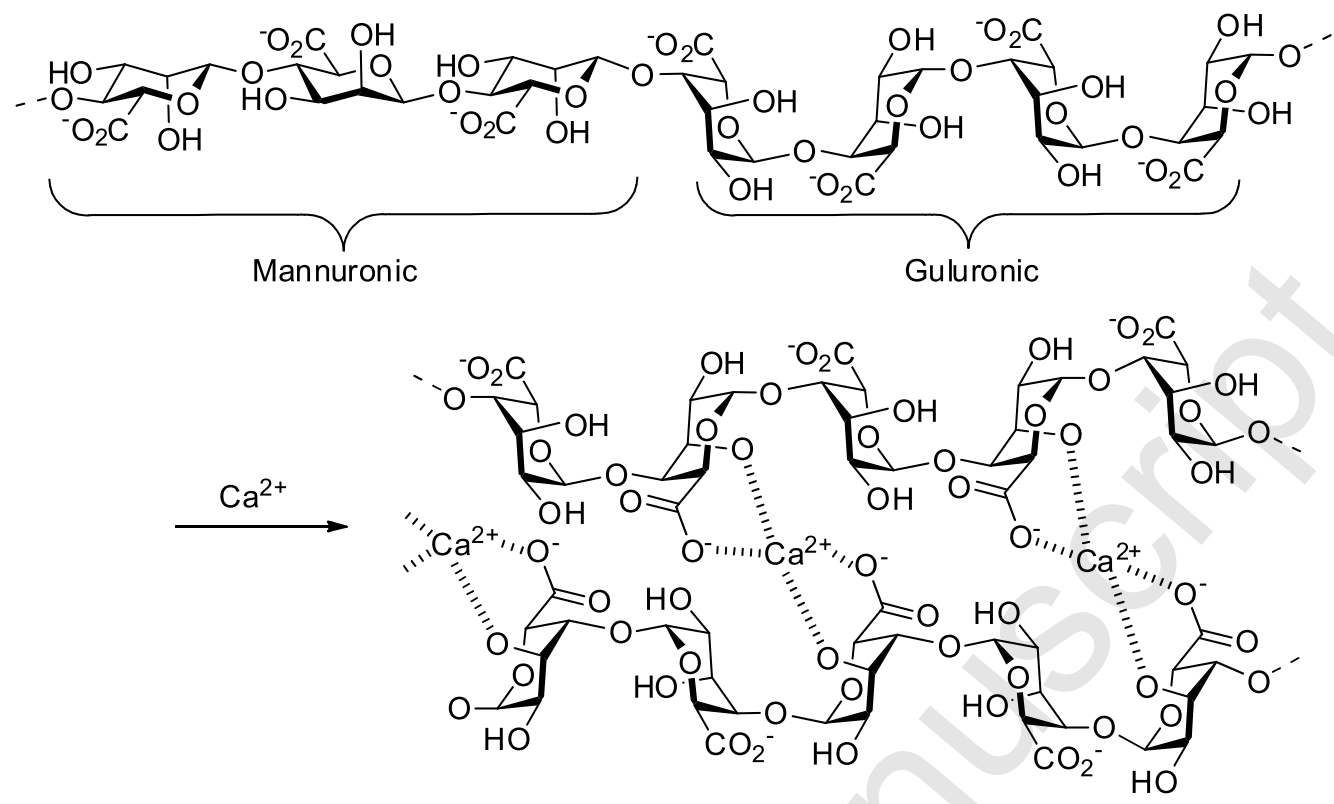

Fig. 4. A conformational model for alginates.

These results led us to turn to neutral polysaccharides. Agar present tertiary conformations close to that of $\kappa$ - and $\mathrm{t}$-carraghenans; laminarines, also called $\beta$-(1,3)-glucans, can organize in triple helix, and was already used to guide the synthesis of hydrophobic nanomaterials (Lehtovaara \& Gu, 2011; Young, Dong \& Jacobs, 2000); starch was also selected since it is well established that it can encapsulate iodine, lipids, surfactants by formation of inclusion complexes (Heinemann, Escher \& Conde-Petit, 2003) (Fig. 5). Once again, no stabilization was obtained using both agar and laminarines. Nevertheless, a slight improvement was observed using starch previously unstructured in a boiling aqueous solution. Indeed, $60 \%$ of NBPT remained unchanged after nine days while Agrotain was decomposed at $60 \%$ over the same period. We hypothesize that this positive effect can be assigned to the presence of helices that prefigure maltocyclodextrins. 
260
Agar

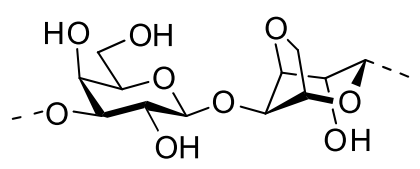

$\beta-(1,3)-$ Glucan

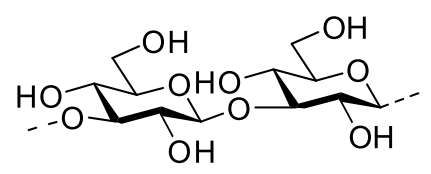

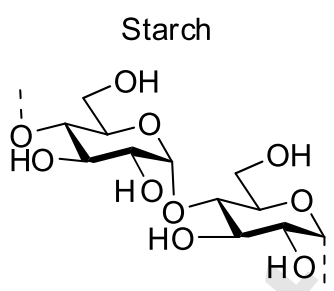

Fig. 5. Main skeleton for agar, $\beta-(1,3)$-glucans and starch.

Therefore, this result encouraged us to use pure cyclodextrins instead of polysaccharides, since they are commonly used in the pharmaceutical industry but also in the food and plant health fields (Shen, Yang, Wang, Zhou \& Chen, 2012). We expected that the lipophilic cavity of a cyclodextrin interact with the NBPT butyl chain to form a complex able to protect the inhibitor from surrounding acidic medium. It was firstly easily established that the more suitable cyclodextrin likely to favorably interact with NBPT was the smaller one containing six glucosyl residues ( $\alpha$-cyclodextrin, CD- $\alpha$ ) (Fig. given in Supplementary Material). Secondly, the optimal molar ratio CD- $\alpha / \mathrm{NBPT}$ was experimentally determined as $1: 1$, and Fig. 6 shows that at least $70 \%$ of NBPT remained stable after four days at $\mathrm{pH} 5.5$, while $60 \%$ of NBPT from Agrotain formulation was hydrolyzed under the same conditions. This corresponds to an increase of $75 \%$ stability

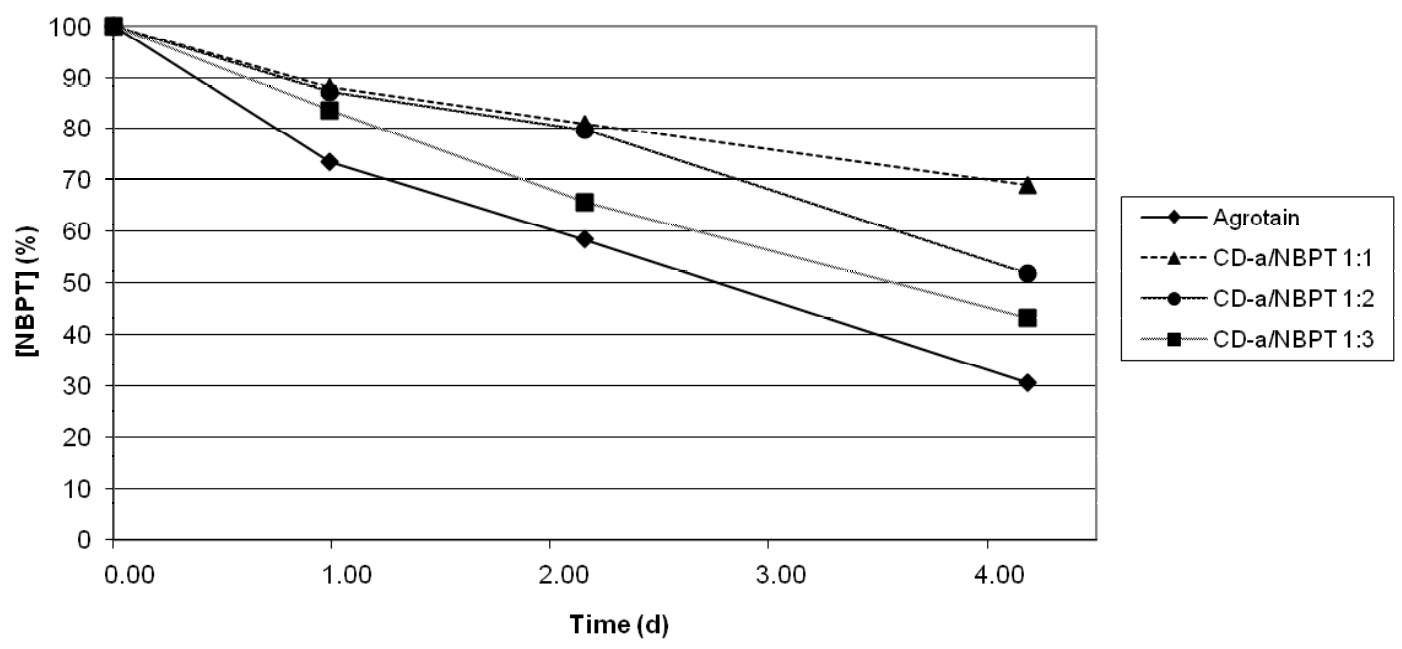


Fig. 6. Stabilization of NBPT according to the molar ratio CD- $\alpha / \mathrm{NBPT}$.

Finally, the precise nature of the suspected complex was determined by ${ }^{1} \mathrm{H}$ NMR thanks to the Job's plot method (Marçon, Mathiron, Pilard, Lemaire-Hurtel, Dubaele \& Djedaini-Pilard, 2009). This approach is based on the correlation between the complex concentration in solution and the chemical shift variations of protons in both the host (CD- $\alpha)$ and the guest

(Fig. 7). A 1:1 complex was thus unambiguously established.

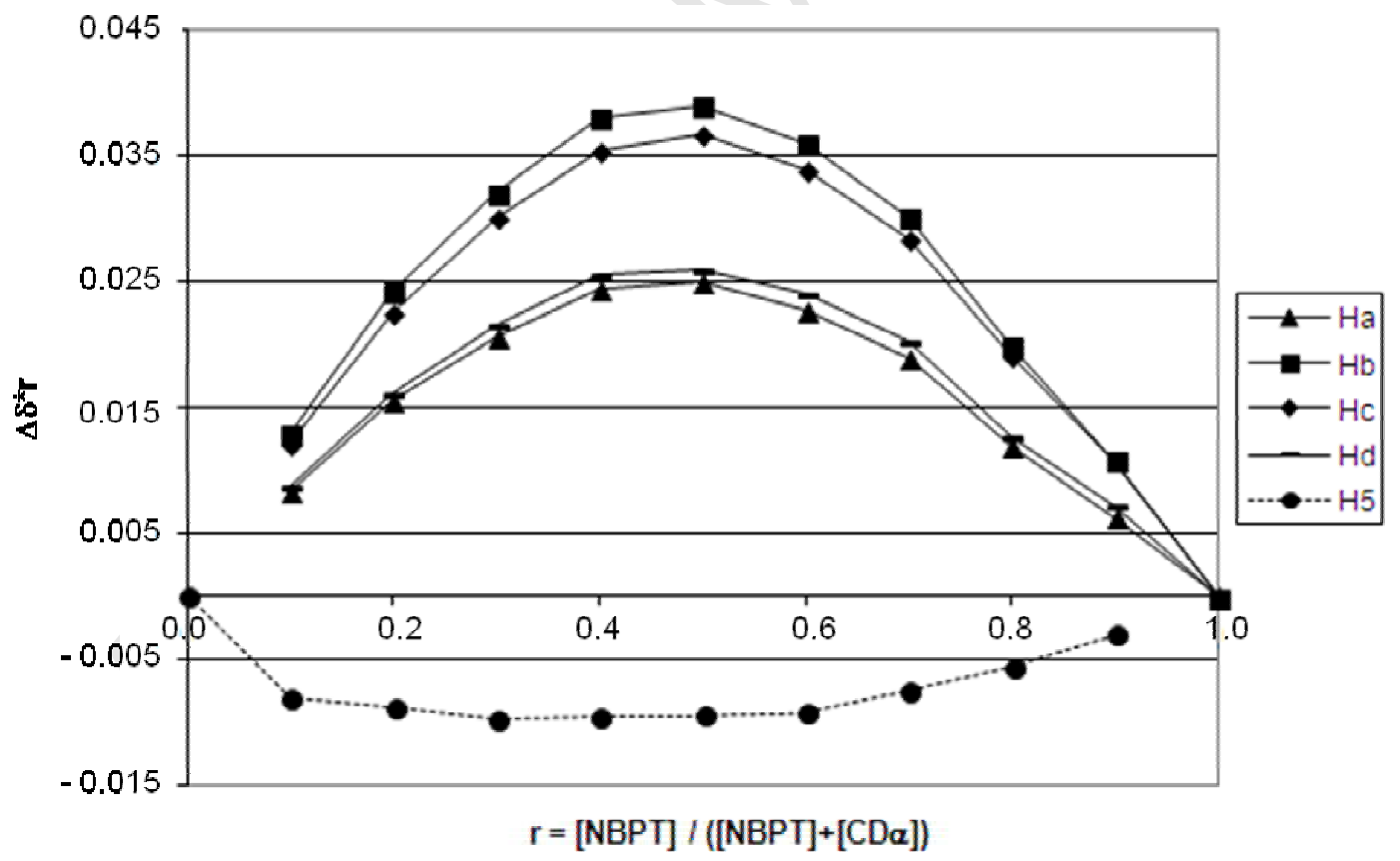

Fig. 7. Determination of the CD $\alpha / \mathrm{NBPT}$ according to the Job's plot method (Marçon, Mathiron, Pilard, Lemaire-Hurtel, Dubaele \& Djedaini-Pilard, 2009). Ha-Hd are for the alkyl chain of NBPT and $\mathrm{H} 5$ for the CD $\alpha$. 
291

Moreover, this study was complemented by a T-ROESY NMR analysis (Fig. 8) in order to identify precise molecular interactions between the inhibitor and its ligand. The resulting spectrum clearly established that H-5 of the maltocyclodextrin are close to the ethyl terminal group of the alkyl chain of NBPT, and that H-3 of the former, exposed from the bigger crown, could interact with all protons of the butyl chain, but more particularly with the core $\mathrm{CH}_{2}$.

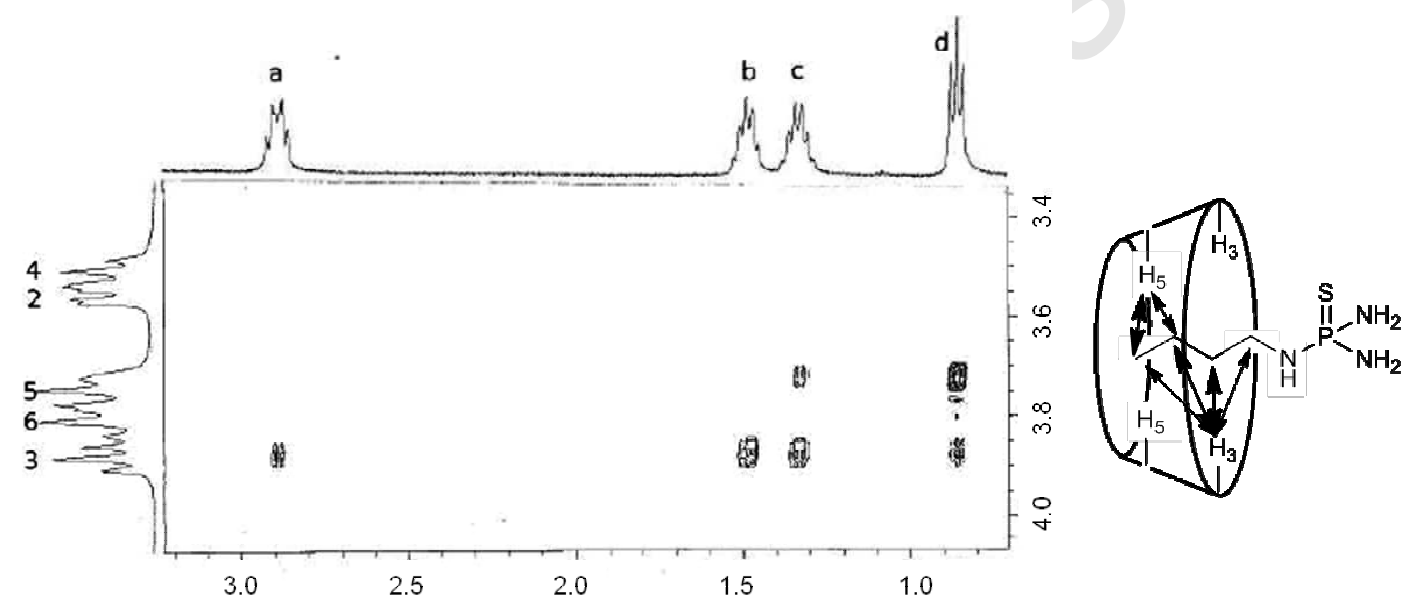

Fig. 8. Focus on NRM T-ROESY spectrum of the inclusion complex CD $\alpha / N B P T$.

Finally, in order to characterize the dynamic of the equilibrium, the association constant $K_{a}$ was determined according to the Benesi-Hildebrand method, applied on ${ }^{1} \mathrm{H}$ NMR signals corresponding to the butyl chain of the NBPT (Benesi \& Hildebrand, 1949). Using a large excess of CD- $\alpha$ and a constant concentration in NBPT, all resulting straights corresponding to the protons of NBPT gave a value of $94 \pm 4 \mathrm{M}^{-1}$, slightly in favor of the formation of the complex. 
Having these physicochemical data in hands, the inhibitory activity of the established more stable complex was evaluated in vitro at $\mathrm{pH} 7$, under optimal conditions for the activity of Jack bean urease. A value of $1.5 \mu \mathrm{M}$ was obtained, i.e. 15 times higher than the $\mathrm{IC}_{50}$ of free NBPT $(100 \mathrm{nM})$. As expected, ligation of NBPT by the $\alpha$-cyclodextrin was accompanied by a significant decrease of inhibiting property, but this lower activity has to be put into perspective with increased stability over time at $\mathrm{pH} 5.5$ and with the significant simplicity of the formulation. To conclude this study, the 1:1 inclusion complex as well as solutions of CD$\alpha /$ NBPT with excess cyclodextrin (ratio: $2: 1$ and 5:1) were deposited on an acidic soil. Monitoring of the urea concentration showed that this simple new formulation had similar efficiency than that of Agrotain (See Supplementary Material). Since activity in vitro was more interesting for the complex, limitations could be attributed to the bacterial activity from the soil.

\section{Conclusion}

Our study is part of the current trend to formulate bioactive compounds, especially in the field of agriculture, as simple as possible using a limiting number of additives, obviously environmentally friendly. In this context, a new formulation of NBPT, a urease inhibitor widely used as fertilizer, was searched with the main goal of increasing its stability over time under acidic conditions. Our approach was based on molecular characteristics of this thiophosphotriamide since it presents a polar phosphoramide function and a lipophilic butyl chain. Therefore, a panel of polysaccharides, neutral or charged, with different physicochemical properties, was tested. Nevertheless, the best results were obtained with the $\alpha$-cyclodextrin used as additive. The 1:1 inclusion complex was fully characterized and presented moderate inhibition activity $(1.5 \mu \mathrm{M})$ but a significant increased stability at $\mathrm{pH} 5.5$ compared to that of commercial Agrotain ( $75 \%$ after 4 days). The resulting inclusion complex 
is a stable solid which is highly hydrosoluble. Application of solutions in an acidic soil finally showed that inclusion complex of NBPT in cyclodextrin- $\alpha$ had similar inhibition efficiency than Agrotain.

\section{Aknowledgements}

$\mathrm{DP}$ is really grateful to the Région Bretagne, Ille et Vilaine, and Rennes Métropole for $\mathrm{PhD}$ fellowship. The present results are part of the AZOSTIMER project, awarded by the Pôle de Compétitivité Mer Bretagne and supported by the TIMAC Agro International (Groupe Roullier). The authors thank Jean-Paul Guégan (ENSCR) for NMR recording.

\section{References}

Abraham, R. T., Benson, L. M., \& Jardine, I. (1983). Synthesis and pH-dependant stabiliy of purine-6sulfenic acid, a putative reactive metabolite of 6-thiopurine. J. Med. Chem., 26, 1523-1526.

Benesi, H. A., \& Hildebrand, J. H. (1949). A spectrophotometric investigation of the interaction of iodine with aromatic hydrocarbons. J. Am. Chem. Soc., 71, 2703-2707.

Cui, S. W. (2005). Food carbohydrates : Chemistry, physical properties, and applications.

Domínguez, M. J., Sanmartín, C., Font, M., Palop, J. A., San Francisco, S., Urrutia, O., Houdusse, F., \& García-Mina, J. M. (2008). Design, synthesis, and biological evaluation of phosphoramide derivatives as urease inhibitors. J. Agric. Food Chem., 56, 3721-3731.

Douglass, E. A., \& Hendrickson, L. L. (1991). HPLC method for the analysis of the urease inhibitor N(n-butyl)thiophosphoric triamide and its metabolites. J. Agric. Food Chem., 39, 2318-2321.

Font, M., Dominguez, M.-J., Sanmartin, C., Palop, J. A., San-Francisco, S., Urrutia, O., Houdusse, F., \& Garcia-Mina, J. M. (2008). Structural Characteristics of Phosphoramide Derivatives as Urease Inhibitors. Requirements for Activity. J. Agric. Food Chem., 56(18), 8451-8460.

Hambleton, A., Fabra, M.-J., Debeaufort, F., Dury-Brun, C., \& Voilley, A. (2009). Interface and aroma barrier properties of iota-carrageenan emulsion-based films used for encapsulation of active food compounds. J. Food Eng., 93(1), 80-88.

Heinemann, C., Escher, F., \& Conde-Petit, B. (2003). Structural features of starch-lactone inclusion complexes in aqueous potato starch dispersions : the role of amylose and amylopectin. Carbohydr. Polymers, 21, 159-168.

Kolc, J. F., Swerdloff, M. D., Rogic, M. M., Hendrickson, L. L., \& Van Der Puy, M. (1985). U.S. Patent 4,530,714.

Lehtovaara, B. C., \& Gu, F. X. (2011). Pharmacological, structural, and drug delivery properties and applications of 1,3-beta-glucans. J. Agric. Food Chem., 59, 6813-6828.

Leinker, M., Reinhardt-Hanisch, A., Hartung, E., \& von Borell, E. (2005). Reducing ammonia emissions by using urease inhibitors. Landtechnik, 6, 342-343.

Marçon, F., Mathiron, D., Pilard, S., Lemaire-Hurtel, A. S., Dubaele, J. M., \& Djedaini-Pilard, F. (2009). Development and formulation of a $0.2 \%$ oral solution of midazolam containing -cyclodextrin. Int. J. Pharm., 79, 244-250. 
Nelson, D. W., \& Huber, D. (1992). Nitrification inhibitors for corn production. National Corn Handbook

Pro, D., Arkoun, M., Huguet, S., Daniellou, R., Nugier-Chauvin, C., Morvan, J., Wolbert, D., Ourry, A., Yvin, J.-C., \& Ferrières, V. (2012). Impact of glycosylation on physico-chemical and biological properties of nitrification inhibitors. Tetrahedron, 68, 7095-7102.

Shen, C., Yang, X., Wang, Y., Zhou, J., \& Chen, C. (2012). Complexation of capsaicin with $\hat{1}^{2}$ cyclodextrins to improve pesticide formulations: effect on aqueous solubility, dissolution rate, stability and soil adsorption. J. Incl. Phenom. Macrocycl. Chem., 72(3-4), 263-274.

Subbarao, G. V., Ito, O., Sahrawa, K. L., Berry, W. L., Nakahara, K., Ishikawa, T., Watanabe, T., Suenaga, K., Rondon, M., \& Rao, I. M. (2006). Scope and strategies for regulation of nitrification in agricultural systems - Challenges and opportunities. Crit. Rev. Plant Sci., 25, 303-335.

Sumner, J. B. (1926). The isolation and crystallization of the enzyme urease. J. Biol. Chem., 435-441. Trenkel, M. E. (2010). Slow- and controled-release and stabilized fertilizers. An option for enhancing nutrient use efficiency in agriculture. International fertilizer industry association.

Young, S.-H., Dong, W.-J., \& Jacobs, R. R. (2000). Observation of a partially opened triple-helix conformation in 1,3-beta-glucan by fluorescence resonance energy transfer spectroscopy. J. Biol. Chem., 275, 11874-11879.

Zaman, M., Nguyen, M. L., Blennerhassett, J. D., \& Quin, B. F. (2008). Reducing NH3, N2O and NO3 -N losses from a pasture soil with urease or nitrification inhibitors and elemental S-amended nitrogenous fertilizers. Biol. Fertil. Soils, 44, 693-705. . 


\section{Captions}

395

396

\section{Phosphotriamide}

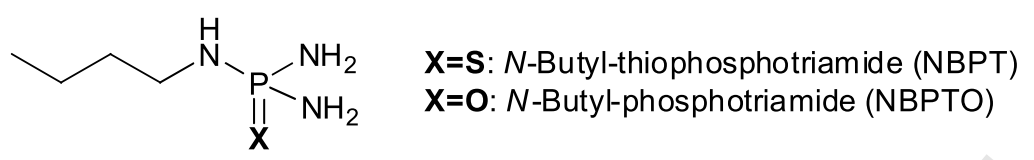

397 Fig.1. Structure of the studied urease inhibitor NBPT. 

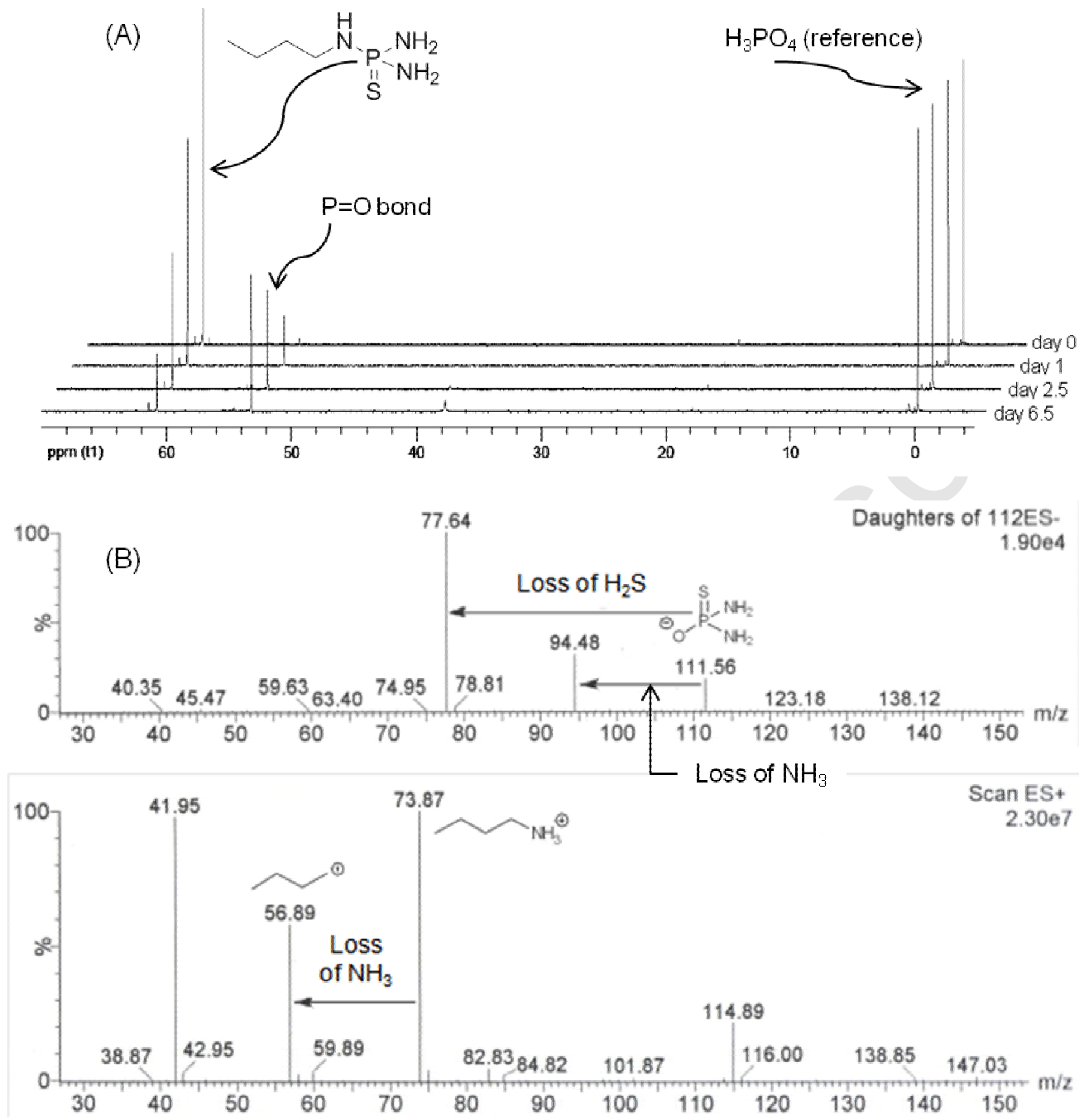

399 Fig. 2. (A) ${ }^{31}$ P NMR monitoring and (B) High Resolution Mass Spectrometry analysis of the 400 degradation of NBPT at $\mathrm{pH} 5.5$.

401 

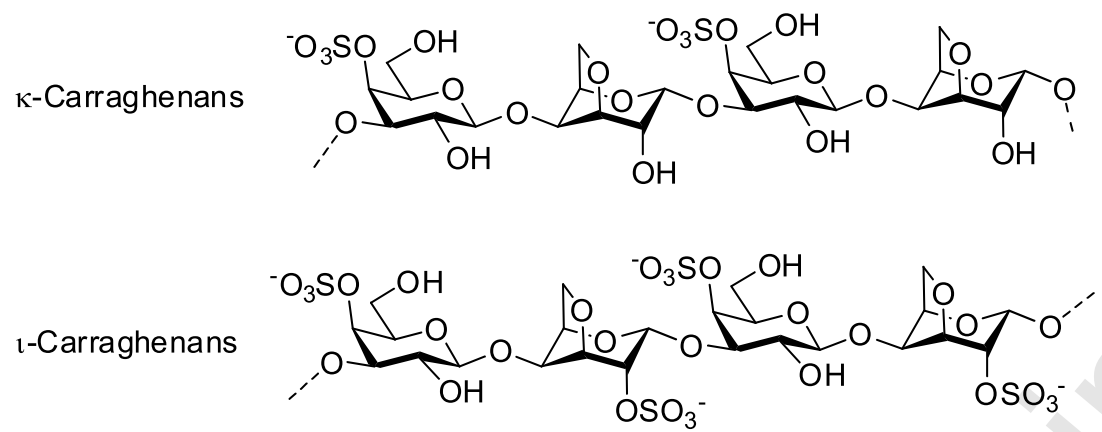

401

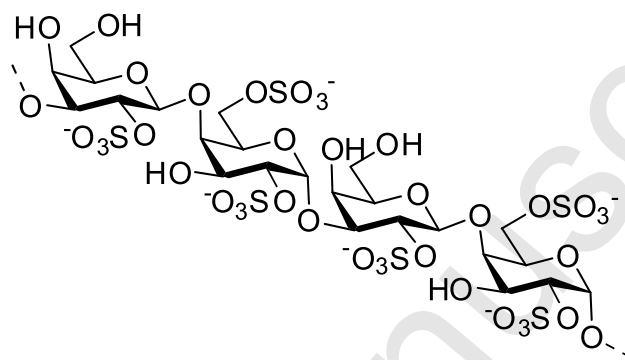

402

Fig. 3. Primary structures of $\kappa-, \mathbf{l}^{-}$, and $\lambda$-carraghenans.

403 

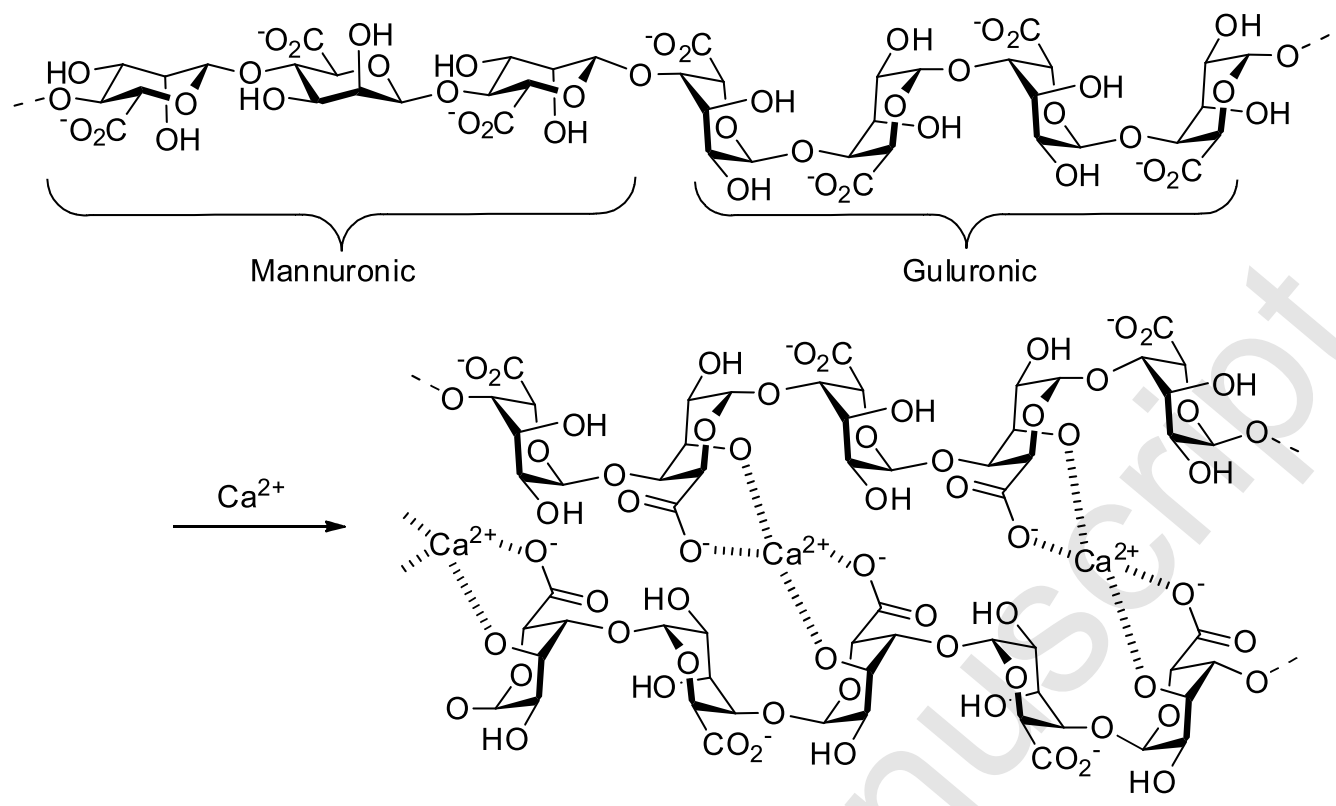

Fig. 4. A conformational model for alginates. 
405
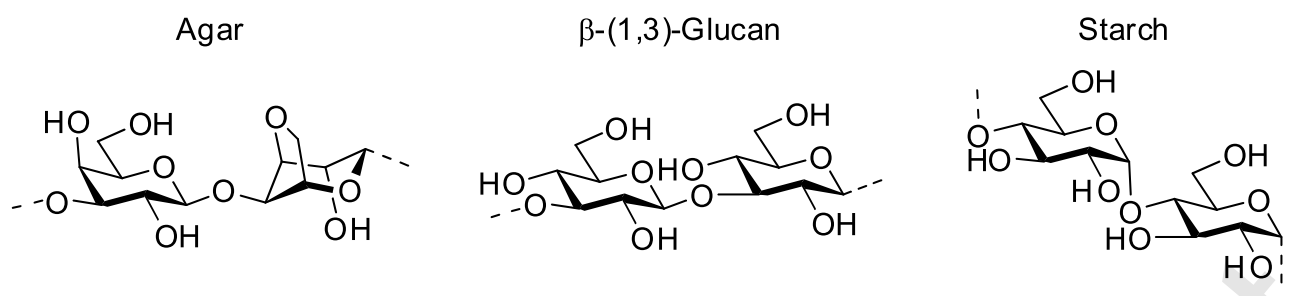

406

Fig. 5. Main skeleton for agar, $\beta$-(1,3)-glucans and starch.

407 


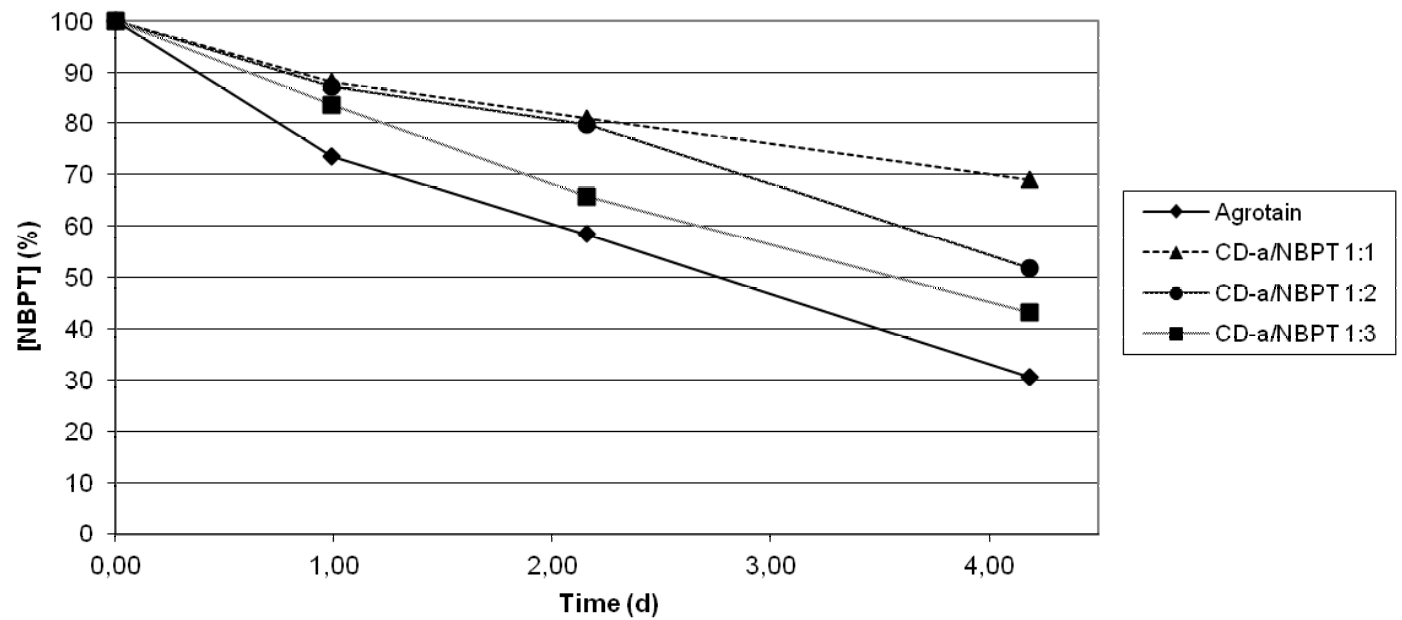

407

408 Fig. 6. Stabilization of NBPT according to the molar ratio CD- $\alpha$ /NBPT. 


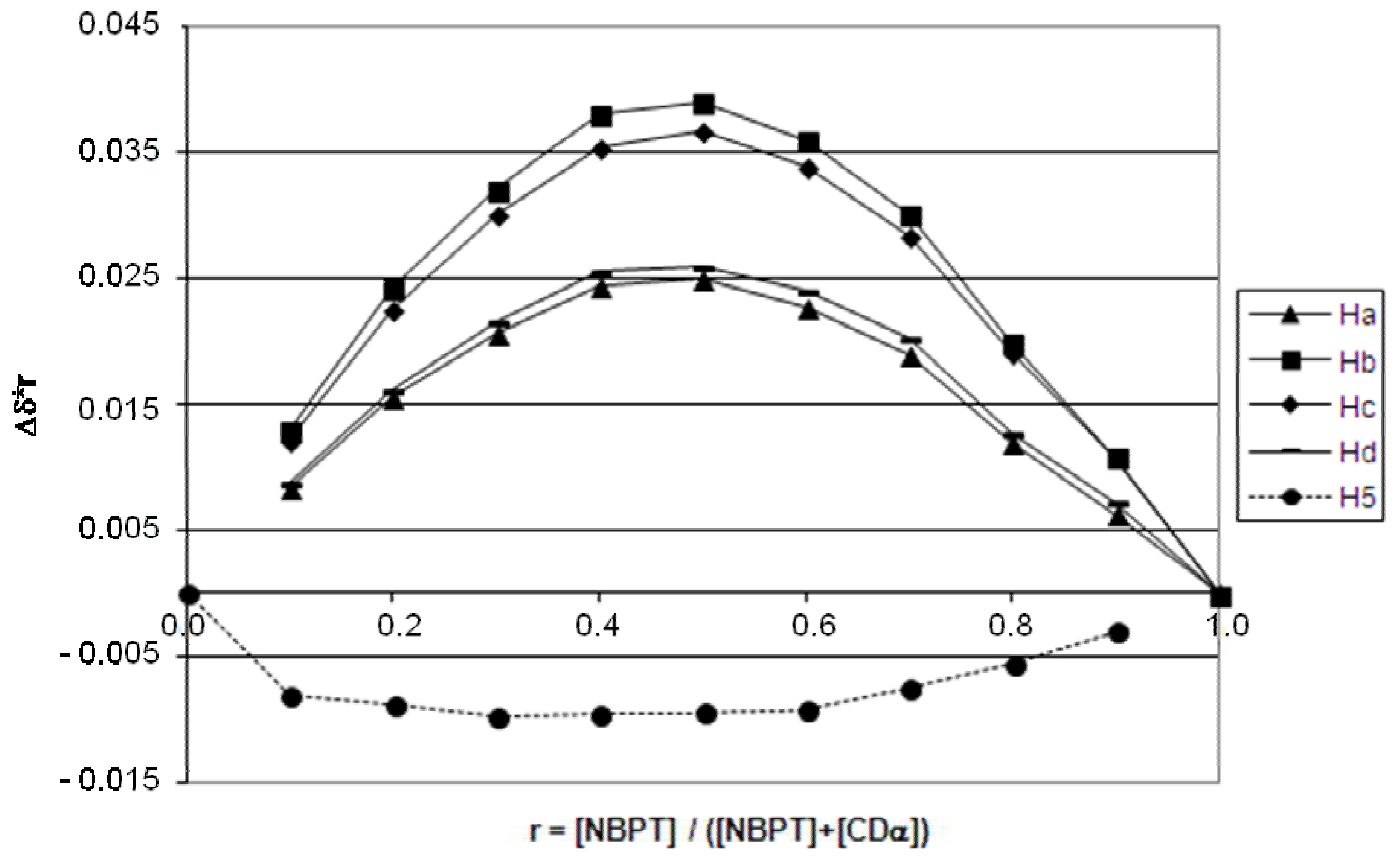

409

410 Fig. 7. Determination of the CD $/$ NBPT according to the Job's plot method (Marçon,

411 Mathiron, Pilard, Lemaire-Hurtel, Dubaele \& Djedaini-Pilard, 2009). Ha-Hd are for the alkyl

412 chain of NBPT and H5 for the CD $\alpha$. 


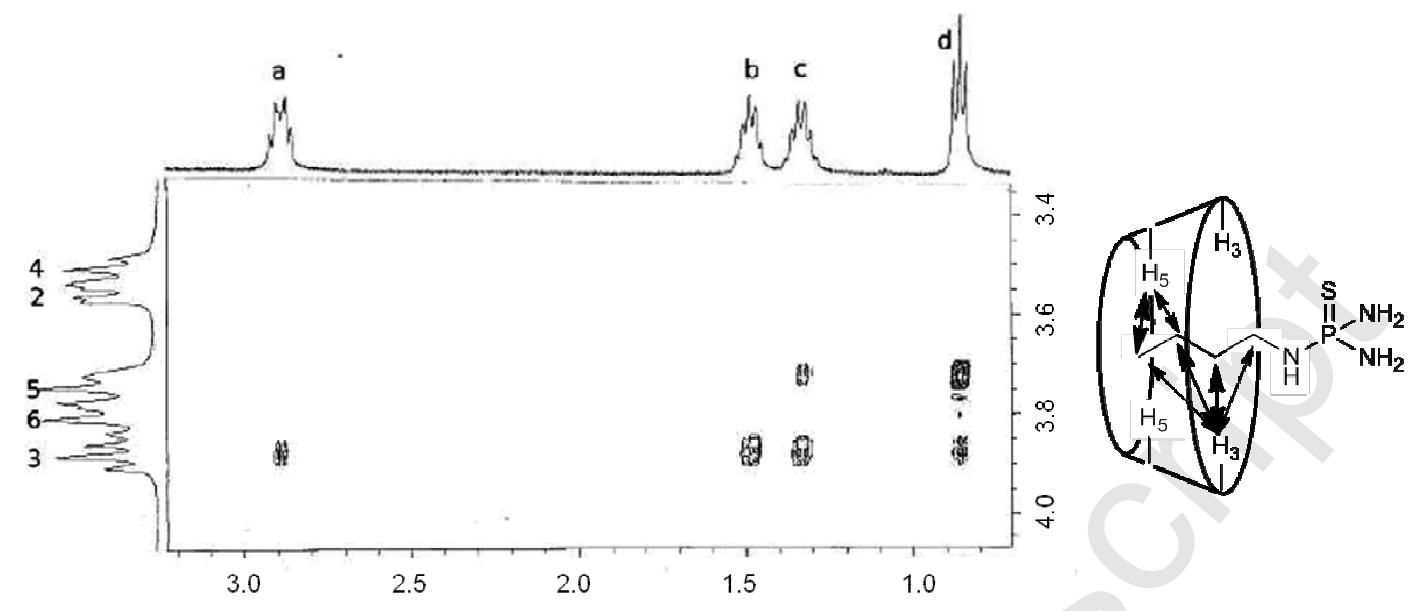

Fig. 8. Focus on NRM T-ROESY spectrum of the inclusion complex CD $\alpha / \mathrm{Nzz}$ 415 